Evaluation
Copyright (C I999
SAGE Publications (London,
Thousand Oaks and New Delhi)
[1356-3890 (1999 I0)5:4; 439-457; 0 I I 767]
Vol 5(4): 439-457

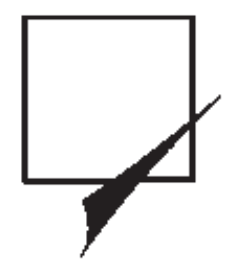

\title{
The Evaluation of Local Policy Making in Europe
}

\author{
Learning from the LEADER Community Initiative
}

\author{
ELENA SARACENO \\ Ricerche Economico-Sociali (CRES), Italy
}

Two recent evaluation studies undertaken for the European Commission, related to the LEADER Community Initiative implemented throughout the 1990s, have provided the basis for the issues discussed in this article. This programme was set up to encourage pilot experiences in the promotion of rural development in the problem areas of Europe, by introducing a set of distinctive features emphasizing the method by which local development is implemented, rather than individual actions. The article argues that development policies with a territorial approach, locally defined objectives, strategies and actions, and involving the participation of several levels of government, have a different set of underlying assumptions and cannot be evaluated with the same tools and concepts that are commonly used in conventional evaluations. Four main methodological problems are discussed: how to define and assess the distinctive features of LEADER individually and as a whole; how to relate such features to development factors; how to ensure the comparison and aggregation of individual programmes at national and European level; and how to assess and produce relevant evaluation information for different governmental stakeholders. The conclusions stress the need to go beyond the accountability logic of conventional evaluations and argue in favour of providing more substantial feedback on the effectiveness of local policy making for the promotion of development, the types of contexts in which the distinctive features introduced by LEADER work best and the comparison of experiences and processes evaluated.

\section{Introduction}

Development policies have recently been characterized by a territorial, integrated approach (as opposed to interventions by sector), the participation of several levels of the public administration (instead of a single administration) and locally defined objectives and strategies, making the various plans financed under one programme extremely heterogeneous. The LEADER Community Initiative, 


\section{Evaluation 5(4)}

launched by the European Union in 1991 to promote rural development, is a good example of this innovative approach.

This article argues that such policies make different assumptions about factors influencing economic development and cannot be evaluated with the same concepts and tools that have been developed for homogeneous, single administration, top-down policies. The underlying assumption is that development processes involve a different mix of relevant factors that are unique and typical of a particular geographical space and time; therefore they cannot be replicated in other contexts and should be conceived of at local level.

The evaluation of these new forms of tailor-made policy making has to acknowledge and understand these different characteristics and define them and their expected results precisely, in order to be able to measure achievements in relation to more traditional approaches. The most common practice in the evaluation of these new programmes is to apply the same conventional method used to measure sectoral interventions conceived within a single administration and applied homogeneously in different sites. Even though some dissatisfaction has been expressed about specific aspects of such an approach (Pawson and Tilley, 1997; Rieper and Toulemonde, 1997), there is no shared consensus within the evaluation community on how to deal with these differences.

Two recent evaluation studies ${ }^{1}$ undertaken for the European Commission have provided an opportunity to focus the problems posed by the evaluation of local policy making, from a conceptual as well as a methodological perspective. The first of these studies consisted of the ex post evaluation of 217 local development plans co-financed by the European Commission and member states in the period 1991-3, known as LEADER I, and asked for aggregated information from all of them at European level. The second consisted of the preparation of a methodology that could serve as a guideline for the evaluation of LEADER II in the current programming period 1994-9. Both were commissioned by the European Commission, the first in 1996, completed in 1998, the second in 1998 and completed in early 1999. Examples from these studies will be used to make different points in the article; however, for a fuller understanding of their methods and results the reader is referred to both works, which are publicly available (see Note 2 ). The aim of this article is not to report on the results of these studies but to make a methodological plea in favour of making a more relevant evaluation of these types of programmes, and for obtaining a more useful feedback from local policy-making evaluations at central level.

It was clear from the beginning that the LEADER Community Initiative (see below for a short description), which was considered an innovative method for promoting economic and social development in very different types of rural areas across Europe, could not demonstrate the asserted superiority of evaluation with conventional tools, because there was no consideration of how the specific features introduced by the initiative had worked. For example, how had the areabased and bottom-up approach, the management by local action groups, the realization of innovative actions and the strengthening of networking activities influenced the results of the realized actions? The inadequacy of the conventional approach was evident also in the need to have comparable results across areas 
and to consider the complex set of governmental institutions which had intervened at all levels and in all member states. Finally, the nature of the evaluation questions that the stakeholders were interested in was different, precisely because the actions had not been conceived at the top and therefore a more substantial feedback than efficiency and effectiveness requirements was demanded.

This article will address four main methodological problems which were tackled in both the above-mentioned studies, indicating for each why the problem is considered relevant, how it has been solved in the work done so far and illustrating synthetically the methodological proposals that arise.

- The first problem is how to define and measure the distinctive features of LEADER. These features are mostly 'intangible' and relate to the conception and method of policy interventions rather than to the actions themselves, even though it is assumed that they will influence substantially the nature and adequacy of these actions. This has been generally referred to as the 'value added' of the approach.

- A second problem is to evaluate (and explain) the way in which local policy making influences social and economic development factors, indicating how distinctive features introduced are connected to such factors. Even though there is a good body of literature on local, endogenous development as a more or less spontaneous process, the analysis of how its characteristics may be turned into policy prescriptions, which can in turn be evaluated, is extremely poor.

- A third problem is to ensure the comparison and aggregation of the results of individual development plans, since the objectives, strategies and actions are specific to each locality, while at the same time each plan is part of a common programme. There is little consensus on how to solve this problem. Precisely because there has been a decentralization of decision making in favour of the local level, it is legitimate that providers of funding would want to know what has been achieved by each group aggregating evaluation information at regional, national or European levels. This, or any other information needs that may be established, requires common questions and issues that allow classification of responses into common categories which can then be compared. The issue is not so much to find appropriate indicators in this aggregation exercise, but rather, as with statistics, to find the appropriate and meaningful classificatory variables and categories of analysis to understand what has been accomplished.

- The fourth problem relates to the presence of different stakeholders in the financing and implementation of local policy making, acting together under the principle of partnership and sharing decision making. These stakeholders are the Commission of the European Union, the member states and the regional and/or local administrations, where they exist as a competent level of the national administration. The question here is complex because of the many public bodies having a function in the implementation of the programme (financing, establishing guidelines, providing services), which in principle should also be the object of the evaluation. On the other hand these same 


\section{Evaluation 5(4)}

stakeholders also represent the demand for evaluation information on the results of local policy making.

Finally, the evaluation questions in which the stakeholders were interested were different, precisely because the actions had not been conceived at the top but at the bottom; this implied a demand for a more substantial feedback than the usual efficiency and effectiveness requirements. The design of policies at local level changes the assumptions implicit in economic development policies for rural areas and, consequently, the nature of the information that the evaluation should produce. Therefore, the evaluation of the distinctive aspects of LEADER should not be treated as an added task to the conventional evaluation, designed as appropriate for top-down homogeneous policies, but as a way of understanding better the mix of factors that are strategic in certain areas in relation to others, and for which no other source of information is available. This would be strategic and relevant information for tailor-made policy making.

It could be argued that LEADER is a small and insignificant programme (about 1\% of the European Union's Structural Funds) and that it is not worth the effort to make a big methodological issue about its evaluation. This is true. However, the LEADER approach has been generally considered a successful and low cost policy (and this has been confirmed by the ex post evaluation). Other EU initiatives and national and international programmes have imitated its approach, and it is likely that in the future this experimental approach will be diffused at national and regional levels. The time, therefore, seems ripe for opening a debate on these problems.

This article will maintain that the four problems raised are relevant for a good evaluation; they should be discussed within the community of evaluators and some consensus should be achieved on the alternative evaluation methods that might be used. The conclusions stress that the evaluation of locally designed policies should be developed further and should become a standard evaluation practice for programmes adopting this approach. This implies a double purpose for their evaluation: in the first place, to respond to the accountability requirements in the use of public funding; and in the second place, to better understand the factors influencing local development in different areas, in order to provide a feedback to the 'top' levels and thus increase the effectiveness of future policy making.

\section{The Characteristics of the LEADER Initiative}

The LEADER initiative ${ }^{2}$ was conceived as an innovative approach to rural development at the end of the 1980s. Previously, policies for rural areas had been equated with agricultural policy, which emphasized the development of the sector rather the territory as a whole. This change was justified as agriculture became a small and declining part of the rural economy. It was thought that a new strategy towards the diversification of economic activities (tourism, small crafts, services, etc.) might be more effective than agricultural policy alone in helping to solve the isolation of and emigration from these areas.

The innovative and distinctive features of LEADER were: 
- A locally based approach, which implied that the project area had to be of small size and homogeneous (defined in terms of population - from 5000 to 100,000 residents - rather than physical size): for example, a mountain community, a small island, an area with a common cultural tradition, an area affected by a specific environmental problem or a particular economic resource.

- A bottom-up approach, implying the participation of local actors, both institutional and from the private sector, in the formulation of strategies and the choice of the actions. Thus all relevant actors within the defined area had to be consulted and projects and funding had to benefit the entire community.

- A Local Action Group, formally established as a partnership of public and private local interest groups, with autonomous decision-making powers in terms of allocation of funds and selection of actions and beneficiaries. In practice this could imply variously composed groups, sometimes dominated by local public agencies, or by a group of local enterprises, or by local private residents.

- An emphasis on innovative actions defined as actions not available through other sources of funding or never tried before in the area: for example, using an under-exploited resource such as a typical local product, building on cultural heritage, or a new form of employment such as telework.

- A global and integrated approach which should include and link together all relevant sectors of the local economy in a coherent strategy for the future, as well as linking the policies themselves, since different sectors often followed contradictory strategies.

- The promotion of networking activities between different local groups and through collective animation activities like seminars, visits and exchanges of experiences. Networking could also include cooperation agreements between different rural areas to promote local products in terms of marketing, joint ventures, etc.

- A global allowance of funds provided to each group for the implementation of its actions, financed partly by the European Union and partly by the national/regional administration of each member state. This freedom in the allocation of funding given to the local group was an important innovation in relation to the standard financing of individual measures.

These distinctive aspects have made the LEADER initiative a form of policy intervention quite different from the other community programmes supported by the Structural Funds, such as the Community Support Frameworks, which are much larger and financially consistent, not necessarily integrated into the different forms of intervention and managed exclusively by public authorities.

The European Commission, and more precisely the Directorate General for Agriculture, conceived and launched the LEADER I initiative. It was a voluntary policy and member states could decide whether or not to apply for it. All of them in the end applied, although with very different degrees of support. This was because this initiative was very often perceived as disruptive to the established procedures for administering policies within the member states on the one 


\section{Evaluation 5(4)}

hand, and an unusual intervention of the EU in local affairs on the other, which was not always appreciated at national level.

Each potential local action group had to elaborate a 'business plan' in which its territorial diagnosis was established, a strategy was identified and individual actions were selected. Overall, 217 programmes were approved in all the 12 member states of the early 1990s, after a pre-selection by the member state and a final selection in which the Directorate General for Agriculture participated. With LEADER II, around 900 plans were approved in 15 states, but the European Commission no longer participated in the selection process, which was a regional responsibility. Programmes had to be completed within three years in LEADER I and five years in LEADER II.

The ex post evaluation of LEADER I showed that the size of the areas in terms of population and dimension turned out to be extremely variable across Europe, but never larger than provinces, counties or districts, and in any case always below the regional level. In some cases this coincided with an administrative unit, but in the majority of cases it was a newly defined project area. The local actors involved proved to be extremely varied, in some cases being strongly dominated by existing public agencies, in others by the private sector (for example a group of cooperatives, an association of enterprises, charismatic leaders). The problems addressed were all formally within the general umbrella of diversified rural development, but in practice this meant that almost any type of action became eligible for funding. The broad categories under which groups had to classify their actions included animation and technical assistance, training and recruitment support, rural tourism, small and medium enterprises and services, transformation and commercialization of agricultural products and other measures. This meant that a very wide variety of actions could be funded, in all sectors of activity, thus giving a very wide range of possibilities to the groups. The area in which most of the funding was spent was rural tourism.

The European Commission has established that the evaluation procedure for LEADER should consider two distinct aspects. The first is a conventional evaluation in the same terms as the evaluation of all programmes financed by the Structural Funds ${ }^{3}$ - this type of evaluation is what we will call throughout this article a 'conventional' evaluation. The Commission also requires that the above mentioned distinctive features should be taken into consideration in the evaluation of LEADER, without specifying with the same level of detail how this should be realized or which features should be considered. While there is a consolidated procedure for realizing the first task, with a reference document produced by the Commission itself, there is no accepted and shared knowledge about how to evaluate the second.

In the ex post evaluation of LEADER I, this double evaluation had to be adopted and a conventional evaluation - with common physical, financial and impact indicators for all groups - was implemented, while an ad hoc methodology was designed to identify, define and then evaluate separately the distinctive features. The result of this double approach is not satisfactory because the linkage between a very good impact, for example in job creation for women, could not clearly be attributed to any one or all of the distinctive features of LEADER. In 
this same example, it was not clear if a high level of participation by women in the preliminary formulation of the plan or in the identification of highly innovative actions was linked to the creation of jobs or more qualified employment. Whilst the integration of the two forms of evaluation is desirable from a methodological perspective, it is very difficult to achieve, given the well-established tradition of conventional evaluations and the professional experience of the evaluators.

\section{Defining and Measuring the Distinctive Features of LEADER}

The first problem that had to be dealt with in the evaluation of LEADER was that none of the above-mentioned distinctive features had been identified in the first place and operationally defined in a sufficiently strict sense. Nor were the expected results from each of these features the motivation for their introduction, nor was it made explicit in which way these would influence rural policy making in relation to other approaches (like the agricultural policy).

Most of LEADER's distinctive features do not consist of material and measurable actions like roads, machinery or buildings, but rather the procedures that should be followed: i.e. the areas to be chosen, the identification of a collective strategy or the management of the 'business plan' through a local group. They relate more to the conception and method of realizing policy interventions than to the actions themselves. These features are 'soft factors' that influence the physical achievements and results. However, the way in which this is realized and measured has been left largely undefined in the official documentation.

The problem is, therefore, how to measure these 'intangible' features. It is assumed that each of them, and all of them together, influence the results of a programme but it is unclear in what way and how this takes place, and whether the implementation of only some and not all of the package will, substantially or marginally, affect the results.

A practical example may help to clarify this problem. Consider a local action group that has developed a project of rural tourism where: (a) know-how about traditional local building techniques has been re-deployed; (b) property holders have participated in the definition of the project and contributed with their private investments to its realization; (c) a collective system of recreation for families with children has been organized with the help of market research experts; and (d) a new image of the area has been elaborated and diffused. The results of these actions have been new visitors to the area, additional income for local farmers and their families, diversified employment for the non-farm population and new forms of integration between the area and the outside world, all of which have improved its attractiveness and capacity for sustainable development.

The indicators established in the business plan following the conventional approach quantify: (i) the number of persons trained in the traditional building trades; (ii) the number of houses that have been restructured; (iii) the number of users of the collective recreation centre; (iv) the number of visitors who have visited the area; (v) the new employment and income generated; and (vi) the cost per unit of output (physical, financial and impact indicators). 


\section{Evaluation 5(4)}

However, something important is missing. How do we know that it is not any type of construction that we are promoting but one that is particularly related to the cultural heritage of the given area? How do we know that each action is coherent and linked with the others? Or that the participation of the property holders has strengthened the cohesion and identity of the population and established a new form of cooperation between economic actors? The LEADER approach is substantially based on the relevance of these 'soft factors' in increasing the efficiency and sustainability of conventional development actions. But these are not accounted for in a conventional evaluation.

The main innovative character of LEADER will not be captured with these indicators and, from a conventional evaluation perspective, LEADER will look similar and comparable to other programmes that do not follow the bottom-up approach, are not managed by local action groups, and do not consider local resources as a strategic factor for rural development. They will tell us the results of actions, but very little about the 'value added' of the local approach or the difference that it has made in relation to conventional top-down sectoral approaches.

In this section, four out of the seven distinctive features that have been identified and briefly described above have been selected to exemplify the chosen evaluation methodology. The pilot, experimental nature of LEADER makes the evaluation of these features extremely relevant since it allows for an assessment as to whether this approach was indeed more effective than other approaches in promoting rural development.

The first task was to operationally define each feature. The second task was to make explicit the motivation and expected outcome of their inclusion in the programme. Finally, there was a set of common questions addressed to participants of the local action groups in order to evaluate whether these results had been achieved. With these three steps the procedure and evaluation questions were clear, explicit and similar for all groups and could serve both for internal evaluation purposes (more qualitative and detailed) and for external (more structured and synthetic) evaluations. In the case of the ex post evaluation study, only four features were analysed (actions, local partnerships, networking and financing), while in the methodology for the LEADER II evaluation (the area-based approach) the bottom-up approach and the integrated approach were added, thus making the seven distinctive features finally agreed as core aspects of the evaluation.

The locally based approach (a project area of small size) is supposed to identify a homogenous area, with an internal social cohesion, a common history and tradition and a shared feeling of identity. The appropriate size is left flexible since population density in rural Europe may vary considerably. The element that provides the cohesion of the project area may be variable across groups but should be clearly indicated.

The area-based approach is assumed to achieve more effectively:

- the valorization of endogenous and distinctive resources, generally underestimated in previous top-down standardized approaches; 
- the acknowledgement that every rural area has its own unique combination of resources and that local actors and institutions are best placed to know the strengths and weaknesses of the area, and consequently that policies should be differentiated according to the areas;

- the adoption of a territorial global strategy which is assumed to be more effective than sectoral approaches.

The bottom-up approach implies the promotion of local actors' participation in policy decision making in their areas. Participation may take place directly or indirectly through representatives of collective private and public interest groups. It may take place only in the preliminary formulation of the programme or throughout its implementation. Animation activities are a strategic component of the bottom-up approach which should facilitate the awareness and mobilization of local actors for potential projects. They should contribute to the elaboration of a territorial diagnosis (strengths and weaknesses, constraints and opportunities), facilitate a negotiation between interest groups on alternative strategies, and help to give legitimacy to their implementation. The participatory approach is expected to:

- help identify relevant policy measures through the consultation of local interest groups;

- acknowledge the differences in the mix of resources available in each area and consequently in terms of policy needs;

- ensure a wide and fair representation of all interest groups, building up consensus among them; and

- strengthen and empower the local level in accordance with the 'subsidiarity' principle.

The local action group is an association of public and private actors within the framework of a partnership which autonomously identifies a common strategy for the area and implements the actions. The partners should be leading figures in the social and economic areas or associations concerned with the environment, culture and social well-being. Local groups take decisions on the allocation of their budget, select beneficiaries and projects, and have management roles. They are not necessarily part of the public administration or the private sector and may be new or already existing bodies.

The local group has proved to be the most original and relevant distinctive aspect introduced by LEADER. Local groups are expected to:

- be more effective in stimulating local initiative than existing public or private agencies because of autonomy in decision making, flexibility, understanding of the opportunities offered by the local mix of resources, sensibility towards innovation and non-sectoral character;

- stimulate a higher degree of decentralization (empowerment) at sub-regional level;

- ensure a wide representation of all interests and therefore facilitate the diversification of the local economy. 


\section{Evaluation 5(4)}

The innovative character of actions has been one of the most difficult aspects to define. In practice, four main meanings have been attributed to innovation:

- actions oriented to the valorization of typical local resources (including the environment, identity, the image of the area);

- actions not considered in previous and current policy measures;

- actions which gave new responses to the commonly acknowledged weaknesses and constraints of rural areas (depopulation, service provision, decline of farming, isolation, desertification ...);

- actions which create a new product, a new process of production or organization and find new markets (the conventional definition of innovation), either by modifying existing technology or by adapting local know-how.

The expected result of emphasizing innovative actions is related to each of these meanings:

- The valorization of local resources is a response to the globalization of markets which could reduce further the competitiveness of rural areas if they produce undifferentiated products; on the other hand it is also a response to the decline of the agricultural sector and policy support. Since local resources are typical and unique to each area and usually have a higher quality content, it is expected that their valorization will increase their market opportunities, fill market niches and obtain higher prices while at the same time increasing the diversification of opportunities in rural areas.

- The innovative character attributed to the actions not considered in other existing policy measures is expected to keep LEADER as a distinct approach and avoid duplications.

- Actions considered innovative because they provide new responses to the traditional problems of rural areas are expected to stimulate solutions which are more sustainable over time (are less dependent on public transfers), contribute to an increase in the attractiveness of rural areas (incoming population and initiatives) and create new ways of providing services and income to low density areas.

- Innovative actions in the conventional sense are not expected to produce radical innovations but rather to produce incremental or adaptive innovations which give rise to new combinations of know-how between local traditional knowledge and widely available and codified technologies, like communication technology.

Looking for quantitative indicators of these specific aspects emerged quite clearly as a misguided approach. The main questions and issues should be identified first; for example, did networking actions contribute to reducing the isolation of local actors? Only after these have been agreed may we want to find quantitative indicators that will be able to measure the realizations, for example, how many contacts with different groups? The different answers to the same question allow for comparisons between groups and the recognition of patterns.

The method proposed for evaluating the distinctive features of LEADER provides a reference framework that shows the rationale of the approach and which 
can be replicated for other features. The definition of the distinctive features and the explicit indication of what are the expected results, sets the framework of what we should be looking for in the evaluation. They represent a sui generis kind of 'indicator' of each feature, established ex ante, which may serve as a basic reference when specifying evaluation questions in order to verify the achievement of the expected results. A set of key questions - which may be found in the methodology for assessing LEADER II - was developed in order to reconstruct the starting situation regarding each specific feature, the process of implementation and the results obtained. This method becomes a proposal for evaluating each one of the distinctive features of LEADER, which of course needs further testing and adaptation - as the features chosen might change - but establishes a procedure that should be followed in general. It should be noticed that the term indicator is used in a particular sense in this case. The answers to the questions and the issues raised have to be aggregated by classificatory variables (for example the types of territory, the types of innovation, the types of groups), very much as in the procedure followed with the responses to a survey, rather than as conventional indicators (for example, the number of beds for tourists), and they may be quantified for aggregation purposes.

The general assumption made by the LEADER initiative is that these specific aspects, either separately or jointly, are the 'value added' of the local approach, increasing the effectiveness and efficiency of rural development policies.

We may imagine that a local group implements the area-based approach but not the bottom-up approach, is involved in networking with other groups but has not identified any innovative actions. The evaluation experience shows that we cannot apply a mechanical logic to define the overall value added because each feature is related to different factors and may have a different 'weight' in the definition of the value added. In the experience accumulated so far, a ranking of the relevance of each distinctive feature in obtaining the results achieved was used as well as a checklist of the features to verify which of them had been implemented.

While the analysis of each distinctive feature has reached a satisfactory level from a methodological viewpoint, the assessment of the combined effect of the 'package' introduced by LEADER needs further methodological work. It is clear that each feature is linked with a specific development factor, and this problem will be analysed in the next section. On the other hand, each distinctive feature is also linked to the typical sequence of the policy planning process reproduced in Figure 1:

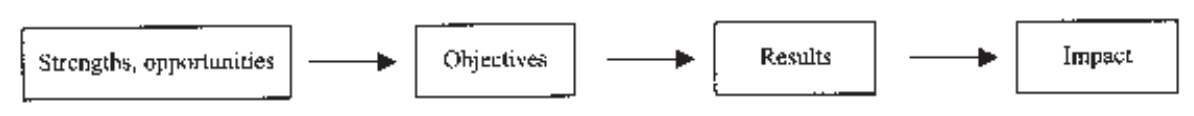

\section{Figure 1}

An assumption should be made about the relationship expected between each distinctive feature and the single phases of this sequence. For example:

- a new perception of endogenous resources through the bottom-up approach 


\section{Evaluation 5(4)}

(strengths, opportunities) may in turn influence the identification of innovative actions (actions), and may influence the diversification of the rural economy (impact for the local level) and contribute to the achievement of the final objectives of the initiative, such as establishing model actions to be transferred (a result at the national and European level);

- the bottom-up approach is linked with the initial definition of strengths and opportunities and may influence the effective mobilization of human resources, the composition of the local action group, which is in turn the basis for an integrated, global approach to development (intermediate objective) and to establish a new approach to rural development (final objectives).

This could also be a first approach to the assessment of the value added of LEADER in relation to other programmes that have not made their assumptions implicit in the distinctive features of these initiatives.

\section{Local Policy Making and Development Factors}

The second methodological problem we considered is to try to evaluate the way in which local policy making - articulated in the seven characteristics described above - influences social and economic development factors. There is a wide and growing literature on local, endogenous development as a more or less spontaneous process. However, the analysis of how these observed characteristics may be turned into policy prescriptions, which can then be implemented and evaluated, is extremely poor (Saraceno, 1998).

In general terms the method used in the evaluations completed so far has assumed that each feature is linked with a particular factor of development.

- The local action group influences the institutional context and the existing social, economic and institutional actors previously considered as representative of that particular context.

- The area-based approach influences the perception of the local resources, in terms of perceived opportunities and constraints for the rural context, no longer treated as a generic set of characteristics typical of any rural area, creating a very specific and adapted perception or diagnosis of the territory in question.

- Networking influences the relationships and terms of exchange between the local area and the external world. It also influences them in quite specific ways: for example, with what markets do local producers have habitual relations, where do locals work or commute to, where do they buy the services they need, etc.

This exercise may be repeated by the evaluator for each distinctive feature in the initial phases of the evaluation, and then assessed at the end of the programme in order to register the changes that have occurred and their influence.

The scope of this exercise has really a much wider significance and is more conceptual in its nature because the choice of adopting a tailor-made policy-making approach implies a radical change of perspective regarding which factors are relevant for making development policies work. To state that local actors or typical 
resources should be factors in the development process is quite different from saying that concentrated investment by outside entrepreneurs will achieve the same objective.

With the reform of the Structural Funds in the late 1980s the EU has acknowledged indirectly the diversity of development processes and has delegated the definition of relevant policies to the regional or local level. If there was any doubt about the relevance of territorial differences before the reform, there should be none left after almost three generations of Structural Funds programming periods, in which policies have indeed followed an increasingly divergent path, adapting to local development factors and conditions.

The recognition of territorial differences implies that the assumption of convergence and the unilinearity of development processes, which had inspired most top-down policies up to the 1970s, is no longer considered valid. Behind the relevance and pilot character of bottom-up approaches there are new assumptions:

- that disparities, usually perceived as negative assets, may be gradually turned into positively constructed territorial differences;

- that less developed areas are not expected to follow the pattern of more developed ones but explore new development paths;

- that differences between territories are reproduced over time and do not disappear;

- that change does not take place necessarily from less to more developed areas but may involve the decline of formerly developed areas.

The belief in the unilinearity and convergence of development processes gave sense to top-down approaches and also a common framework of reference for the evaluation of such policies. The agricultural (sectoral) specialization sustained by European common policies for all rural areas made bottom-up approaches irrelevant, because all rural areas were considered similar and going in the same direction, with minor differences. The recognition of territorial diversity as a relevant factor undermines this common frame of reference, both in the assumption of spatial similarities and in the evaluation of no-longer-common policies. These changes in the theory of development, implicitly acknowledged by the two reforms of the Structural Funds, have questioned the previous homogeneous and undifferentiated policy approach and opened the way for tailormade policy making.

This change of perspective has increased the relevance attributed to bottomup approaches and enhanced the interest in meaningful feedback from the results of an evaluation. The experience of ongoing evaluations indicates that, so far, the practice of adding up quantitative indicators has prevailed. What has frequently been done at an individual local level is replicated at regional and other territorial levels. There is a conceptual flaw in this procedure because it continues to operate within the same logic of top-down approaches. Territorial diversity (the valorization of endogenous resources) is never accounted for in the aggregation of data and we go back to the assumption of an undifferentiated space and the irrelevance of contextual factors.

In the new situation, the function of the evaluation is not only to add up 


\section{Evaluation 5(4)}

indicators but also to consider territorial differences in the development process or in the mix of available resources in order to understand which policies are relevant where. In this case, an evaluation only in terms of conformity and accountability would be clearly insufficient and would miss feedback from 'the bottom', not just on implementation, but on which actions have been more effective in relation to the types of context, and what has been achieved in terms of rural development.

If we pose the problem in terms of comparing different patterns of development, then a territorial typology is a first and basic variable and should include: the new sequences or stages of development generated at local level (patterns, relevance of different sectors); what types of exchanges exist between local and external areas; and so on. What is important is to define meaningful categories for aggregating evaluation results at different territorial levels. In this way, the familiar evaluation of success and failure gives way to a more gradual differentiation of achievement: 10 new jobs in a remote non-diversified area are more significant than 50 new jobs in a diversified well-integrated area.

It is one thing to define a policy at central level (in the top-down approach), then verify the implementation of the policy at local level (conformity) and its effectiveness and efficiency with appropriate indicators. It is another thing to provide general guidelines and procedures at EU level, which are then interpreted and implemented differently in each member state, and have each local group define its own programme of actions that is different for each individual area (in the bottom-up approach). In the latter case, an evaluation in terms of conformity and accountability alone would be clearly insufficient.

\section{The Aggregation of Results at National and European Levels}

A different methodological problem arising from 'tailor-made' policy making is how to ensure the comparison and aggregation of the results of individual programmes which are different from each other at regional, national or European level. The information here requires common questions and issues which will allow a classification of responses into homogeneous categories that can then be compared. The issue is not so much to find appropriate indicators in this aggregation exercise but rather, as with statistics, to find the appropriate and meaningful classificatory variables and categories of analysis through which to understand what has been accomplished.

It has been customary at national and EU level to ask for individual programmes' evaluations which provide plenty of information about progress and physical realizations and are easy to aggregate, but are difficult to synthesize meaningfully because the basic information has not been collected with relevant classificatory variables.

There are three different aspects to this problem. One is how to aggregate the results of individual programmes. This can be solved if we create ex ante a minimum core of information and indicators that all individual plans within a programme must provide. Common questions and indicators are the most reasonable solution to this aspect of the problem. 
The second aspect of the problem is that the aggregation and comparison of results are not just a question of consolidating financial data or adding up indicators. As already mentioned, the creation of classificatory variables and typologies is essential in order to create relevant categories of analysis, which cover the whole range of possible answers. This procedure allows us to place individual performances in the appropriate categories and then to compare the results between, for example, types of areas, local action groups and innovations.

The third aspect of the evaluation is how to distinguish the information needs of different stakeholders. In general, the current literature and state of the art distinguish between: on the one hand, the evaluation needs of the individual group, which are pictured as qualitative, participatory, oriented towards increasing the efficiency of the management, reflect on errors and capitalize on learning from previous actions in order to improve future policy making; and on the other hand, the evaluation needs of external stakeholders, which are pictured as quantitative, based on external evaluators and requiring 'accounting' information that is of little use to the individual group. This polarization of positions does not correspond to the real needs of stakeholders (which, by the way, are very difficult to make explicit in all cases). There is no reason to believe that institutional stakeholders will not be interested in well-classified information about how animation activities, for example, influence the realization of actions. On the other hand, it would be extremely productive for an individual group to try to explain why, for example, the costs per unit of training are so much higher for them than for another group in the same country.

The often-mentioned conflict between participatory self-evaluations at local level and external evaluations is greatly reduced when we enlarge the scope of the evaluation exercise to include all the stakeholders in the initiative, EU included. We found a great deal of complementarity between the different methods of evaluation. Those groups which voluntarily and periodically undertook evaluation exercises were also those that provided the best and most reliable information to external evaluators. Nor is there good reason for excluding the administrative and institutional levels (at national, regional and European level) from the evaluation exercise, for the part they played in the design and implementation of the initiative (see below).

These aspects still need a lot of work in order to achieve consensus as to standard practices, but very little real and substantial feedback from evaluations at local level will be possible until they are tackled systematically. The solution found with the ex ante evaluation appears as a partial response to some of these problems and is not satisfactory because it deals mostly with the internal coherence and the establishment of indicators for each single programme. In this way, even with a considerable cost allocated to evaluations, the problem of providing comparable information in common and well-defined categories of analysis and relevant issues for future policy making has not been achieved. The problem of aggregation in the sense used in this article is different from that raised by the literature about cluster evaluation (Sanders, 1997) because in our case it is not one programme implemented at different sites but explicitly 
differentiated programmes which follow similar procedures in the definition of policies.

\section{The Evaluation of Government Stakeholders}

The last problem to consider arises because of the presence of different stakeholders in the financing and implementation of local policy making, acting together under the principle of partnership and shared decision making.

There is a division of labour (who does what) among stakeholders and institutional 'actions' require an evaluation just as much as those of local groups. In the LEADER I initiative for example, the Commission at EU level conceived the approach, participated in the selection of the plans, organized the technical assistance and animation of a network at European level and provided part of the financing and the technical assistance to groups and to other administrations for the implementation of the programme. The national administrations had to take up the delegated authority to publicize the initiative, choose the potential beneficiary groups, provide the necessary technical assistance and monitor and report on the implementation.

The ex post evaluation of LEADER I has indicated that each government acted as a 'filter' in the interpretation of the philosophy of the initiative, tried to adapt it to already existing policy measures in order to reduce the administrative burdens of the initiative, provided different guidelines for the groups, and delivered its share of co-financing at different times and within a different set of constraints. This indicates that the various intervening institutional levels contribute, sometimes very substantially, to the results and impact observed at the local level. They should therefore be evaluated and compared. The problem with intergovernmental evaluations (Rieper and Toulemonde, 1997) is that they bring up extremely sensitive issues which very few of the stakeholders are willing to raise in the transparent context of an evaluation. The problem in this case is not so much methodological as political and influences very significantly the results achieved at the local level by local groups.

Another aspect of this problem is that the institutional stakeholders are not only providers of services that should be part of the evaluation, but are also the main subjects with an interest in the results of an evaluation. In the methodological proposals for the evaluation of LEADER II, this aspect was dealt with by confronting the various government administrations with the information requirements they had in order to construct a consolidated and shared list of information items at the regional, national and the EU level. This proved to be a difficult task, again, not so much because of the methodological aspects involved, but more due to a lack of reflection on the changes involved in local policy making by regional and national authorities, little experience with systematic evaluations, and fears that control aspects of evaluation would always count more significantly than meaningful feedback from an innovative policy. 


\section{Conclusions: The Double Function of Evaluation in Bottom-up Policies}

The conventional approach to the evaluation of policies, conceived mainly within an accountability rationale, appears limited and inadequate for the evaluation of bottom-up policies. The 'objectives-actions-results' sequence, typical of the conventional approach, assumes the irrelevance of local development factors in influencing the uptake and results of a programme. Bottom-up policies are based on a different assumption that considers local factors, such as the institutional context, the economic and social actors and the available resources, as relevant factors, different from place to place, which make a substantial difference to the design, implementation and achievements of policies.

The evaluation of a programme like LEADER, with the requirement that its distinctive features should also be considered, has provided an opportunity to focus on the problems of the evaluation of bottom-up policies. While it is clear that the conventional approach, with its accountability objectives, remains a basic evaluation need in bottom-up programmes, there are other substantial problems and needs that an evaluation should also assess, and not just as an additional requirement. The ex post evaluation of LEADER and the preparation of common guidelines for the evaluation of LEADER II have provided an opportunity for making some progress in the methodology requirements for the evaluation of local policy making. The main issue that remains unexplored, given the approach followed by the main clients of these evaluations, is the lack of integration and the 'asymmetry' of knowledge between what we have called the conventional evaluation and the assessment of the distinctive features of LEADER. Further work on this aspect would provide valuable information on how the areabased approach, for example, is linked to or influences the quantitative and qualitative results of implemented actions. A positive influence would make a strong case in favour of the decentralization of policy making.

Four methodological problems and needs have been considered in this article:

1. The need to define the nature and expected result of the distinctive features of each of these initiatives and to make explicit the linkage between these and the factors of development which they are supposed to influence;

2. The need to make explicit the different conceptual assumptions about economic development inherent in different types of policies, for example, in the top-down and bottom-up case, in order that a type of feedback other than that of accountability is addressed explicitly in the evaluation;

3. The need to resolve the question of aggregation and comparison of the results for different types of stakeholders; and

4. The need to evaluate the different institutional and governmental levels which both intervene in the programmes as stakeholders and also represent the main clients of the evaluation exercise.

The solutions given to these problems in the work discussed here are incomplete and need further elaboration, but the nature and scope of the task ahead should be clear. In the case of tailor-made policy making, where every context is assumed 


\section{Evaluation 5(4)}

to be different, the information needs of the stakeholders financing a programme cannot confine themselves to the question of conformity, effectiveness and efficiency in abstract terms. The stakeholders should require more substantial feedback from the evaluation on the relevance of these types of policies for rural development and the difference that the assumption of the diversity of contexts makes, in order to compare experiences and reconstruct some intermediate generalizations that could be used for future policy making.

The experience of evaluating LEADER has shown that the evaluation exercise in programmes that have adopted a bottom-up approach has at least two main functions:

(i) To provide information on the results and impact of realized actions at local level, considering the influence on such actions of specific aspects, both individually and as a whole, in order to be able to establish whether the adoption of the participatory, locally based approach leads to a more effective and sustainable form of development in relation to other approaches; and

(ii) To provide information (the only information that would be available) on the real processes which are taking place at local level as a result of this development approach.

This second function is of the highest importance. Once we have dropped the assumption that all development processes are similar we cannot go to the other extreme and say that they are all unique and different from one another. In order to find out which patterns are emerging, it is necessary that evaluation, the only tool which is mandatory for all programmes, be able to provide information also on the comparison of such local patterns, relevant territorial differentiation and intermediate generalizations that can be derived from the unique cases. For this we need significant categories of aggregation rather than homogeneous indicators that can be added up. Whilst it is good practice to let each area define its own priorities and strategies, with the evaluation a different approach should be adopted. We can then have the data to help us understand the alternative ways of reaching the same objectives and which policies and actions have the highest impact on certain types of recurring problems. If we let the evaluation exercise remain only as an accounting exercise we shall have missed valuable feedback on ongoing processes of spatial differentiation, about which we know very little.

\section{Notes}

1. The first work is: General Report, Ex Post Evaluation of LEADER I, Brussels (now available on the Internet's European Commission site, Directorate General for Agriculture, evaluations) by J. C. Bontron, J. L. Déthier, E. Saraceno and H. von Meyer, completed in 1999; the author was the scientific coordinator; the second work mentioned, Assessing the Added Value Added of the LEADER Approach, has been published by the LEADER European Observatory in Brussels, within the framework of the technical assistance provided to public administrations and local groups (June 1998) by the Commission during the implementation of LEADER II. In this case, the author acted as working group co-ordinator and drafted the final report.

2. European Commission, Communication to the Member States (91/C 73/14). 
3. The methodology for the evaluation of programmes co-financed with Structural Funds is contained in an official document of the European Commission published in 1994: STAR Doc.VI/3479/94REV3.

\section{References}

Pawson, R. and N. Tilley (1997) Realistic Evaluation. London: Sage.

Rieper, O. and J. Toulemonde (eds) (1997) Policies and Practices of Intergovernmental Evaluation. New Brunswick, NJ: Transaction Publishers.

Sanders, J. R. (1997) 'Cluster Evaluation', in E. Chelinsky and W. Sadish (eds) Evaluation for the 21st Century. London: Sage.

Saraceno, E. (1998) Artigianato e piccole imprese. Ruolo e strumenti per lo sviluppo rurale [Craft Industries and Small Enterprises: Roles and Tools for Rural Development], Quaderno informativo 6.

ELENA SARACENO has been director of CRES, a private socioeconomic research institute in Udine, Italy since 1978. She has lectured at the Universities of Ancona, Bologna, Rome and Udine in Economic Geography and Regional Development. She has done extensive field research in the fields of return migration, part time farming, mountain areas, local labour markets and rural development, in cooperation with various research institutions in Europe. During the 1990s, her involvement with technical assistance, monitoring and evaluation of programmes co-financed by the European Union has gradually grown in relevance. At present she is temporarily working at the Forward Studies Unit in the European Commission. 